\title{
Research on Hydrodynamic Performance of the Interaction between Ducted Propeller and Rudder based on CFD
}

\author{
Yonghe Xie ${ }^{1}$, Guibiao Wang ${ }^{1}$ and Wei Wang ${ }^{1^{*}}$ \\ ${ }^{1}$ School of Naval Architecture and Ocean Engineering, Zhejiang Ocean University, Zhoushan, Zhejiang, China
}

(Manuscript Received September 25, 2013; Revised October 20, 2013; Accepted November 27, 2013)

\begin{abstract}
The computational fluid dynamics software FLUENT is used to calculate and compare the hydrodynamic performance of the propeller-rudder system of a 42-m trawler, which is installed with a ducted propeller. The effects of rudder on the hydrodynamic performance of the ducted propeller and the wake flow behind the propeller are firstly investigated. In addition, the different rudder angles are also considered to further study the performance of this system.
\end{abstract}

Keywords: ducted propeller-rudder system; hydrodynamic performance; wake field; rudder angle

\section{Introduction}

The rapidity and maneuverability are of great concern in ship navigation. The hydrodynamic performance of propeller and rudder is an important research topic for many years [1]. The ducted propeller can be applied and installed in the trawlers, which may be the most widely used fishing vessel. This propeller can provide a powerful capacity to resist the heavy loads. In recent, the related research on the interaction between propeller and rudder mainly focus on in the generic propeller [2-4], however, there is few correlation study on the ducted propeller and rudder.

Due to the installation of the duct, the hydrodynamic performance of ducted propeller-rudder system must be different from the generic propeller and rudder. In this paper, the ducted propeller-rudder system of a $42-$ $\mathrm{m}$ trawler is selected and studied.

\section{Theory of CFD and Numerical Model}

\footnotetext{
"Corresponding author. Tel.: +86-580-2550008-2550009, Fax.: +86-580 2551319, E-mail address: g4ww@sohu.com Copyright $\odot$ KSOE 2013.
}

\subsection{Theory of CFD}

Equations (1) and (2) are continuity equation and RANS equations, respectively,

$\frac{\partial \bar{u}_{i}}{\partial x_{i}}=0$

$\rho \frac{\partial \bar{u}_{i}}{\partial t}+\rho \bar{u}_{j} \frac{\partial \bar{u}_{i}}{\partial x_{j}}=-\frac{\partial \bar{p}}{\partial x_{i}}+\mu \frac{\partial^{2} \bar{u}_{i}}{\partial x_{j} \partial x_{j}}-\rho \frac{\partial \bar{u}_{i}^{\prime} \bar{u}_{j}^{\prime}}{\partial x_{j}}+\rho \bar{f}_{i}$

where, ??? is Reynolds average velocity, ??? is fluctuating velocity, and ??? with Reynolds Stress.

Compared with the standard k- $\varepsilon$ turbulence model, the RNG k- $\varepsilon$ turbulence model considers the swirling of the averaged flows with the modified turbulent viscosity[5]. Therefore, the RNG k- $\varepsilon$ turbulence model is utilized to deal with the rotational movement of the propeller, and its transport equation of $\mathrm{k}$ and epsilon are shown in Equations (3)and (4),the detailed derivation process and parameter selection can be found in [6]. 
Table 1. Geometric parameters of propeller of $42 \mathrm{~m}$ trawler

\begin{tabular}{cccc}
\hline \multicolumn{4}{c}{ Ka4-55 ducted propeller } \\
\hline $\begin{array}{c}\text { diameter } \\
(\mathrm{m})\end{array}$ & $\begin{array}{c}\text { Hub diame- } \\
\text { ter }(\mathrm{m})\end{array}$ & pitch $(\mathrm{m})$ & $\begin{array}{c}\text { expanded area } \\
\text { ratio }\end{array}$ \\
3 & 0.48 & 4.26 & 0.55 \\
\hline
\end{tabular}

$$
\frac{\partial(\rho k)}{\partial t}+\frac{\partial\left(\rho k u_{i}\right)}{\partial x_{i}}=\frac{\partial}{\partial x_{j}}\left[\alpha_{k} \mu_{e f f} \frac{\partial k}{\partial x_{j}}\right]+G_{k}+\rho \varepsilon
$$

$$
\frac{\partial(\rho \varepsilon)}{\partial t}+\frac{\partial\left(\rho \varepsilon u_{i}\right)}{\partial x_{i}}=\frac{\partial}{\partial x_{j}}\left[\alpha_{\varepsilon} \mu_{e f f} \frac{\partial \varepsilon}{\partial x_{j}}\right]+\frac{C_{1 \varepsilon}^{*}}{k} G_{k}-C_{2 \varepsilon} \rho \frac{\varepsilon^{2}}{k}
$$

\subsection{Numerical Model}

The geometries of the ducted propeller and rudder of a 42-m trawler are shown in table1 and Table 2. The gap between the center line of propeller shaft and rudder stock was $1.3 \mathrm{~m}$. The geometry model as shown in Fig. 1 is constructed by Gambit, the preprocessing module integrated in FLUENT. This model is then exported into ANSYS-ICEM to generate the mesh, as shown in Fig. 2
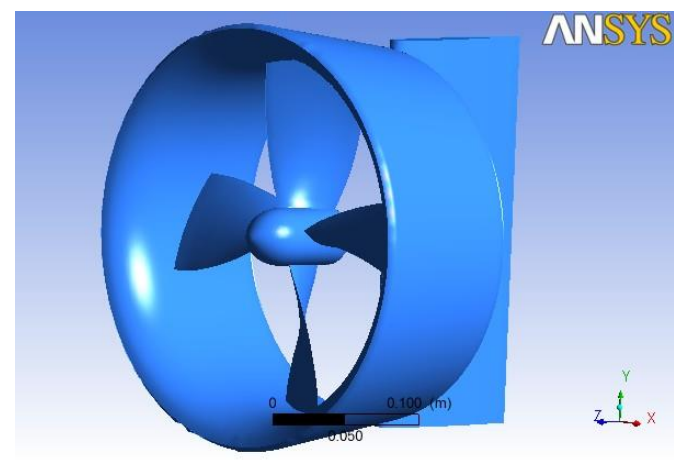

Fig. $13 \mathrm{D}$ model of propeller-rudder system

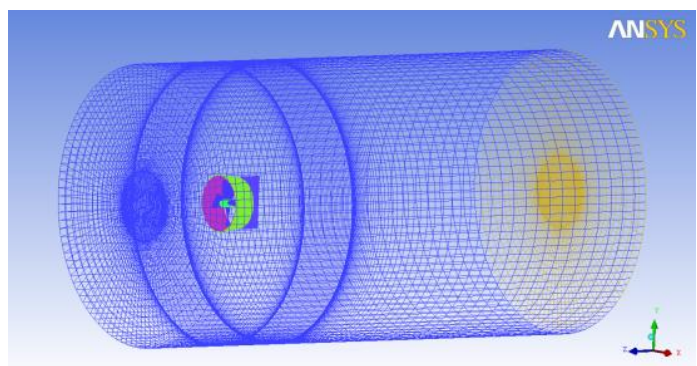

Fig. 3 Grid of the computational domain
Table 2. Geometric parameters of propeller of $42 \mathrm{~m}$ trawler

\begin{tabular}{ccc}
\hline \multicolumn{3}{c}{ Rudder with profile NACA-18 } \\
\hline size features of & rudder area & aspect ratio \\
rudder $(\mathrm{m})$ & $(\mathrm{m} 2)$ & 2.2 \\
$3.30 \times 1.50$ & 4.95 & \\
\hline
\end{tabular}

Computational domain that chose is a cylinder which is shown in Fig.3, the distance between the inlet plane and the propeller is $2.5 \times \mathrm{D}$; the cylindrical computational domain is $11.5 \times \mathrm{D}$ in length and $6 \times \mathrm{D}$ in diameter around the duct propeller and rudder. The domain is composed of three sub-domains, which are the domain with propeller and the inner wall of duct, the domain with the ektexine of duct and rudder and the domain without flow field. For the mesh generation in ANSYS-ICEM shown in Fig. 2 and Fig. 3, the peripheral computational domain which using hexahedral cells as the structure mesh, and the other two domain used unstructured mesh contained tetrahedral cells and prism cells as the boundary layer. The mesh of domain had a total of around 1.47 million elements.

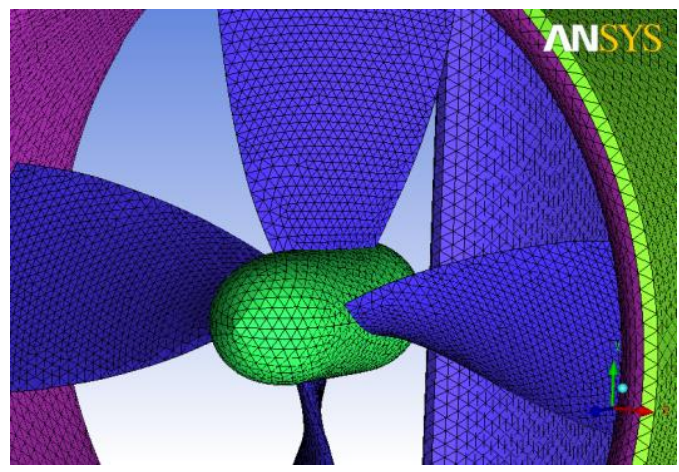

Fig. 2 Surface grid of propeller-rudder system

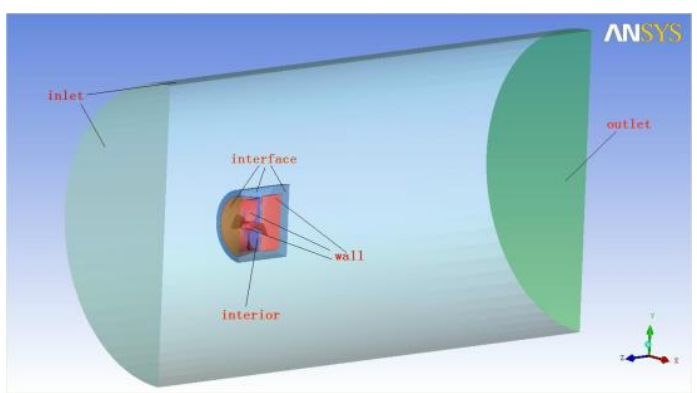

Fig. 4 Boundary condition of the computational domain 


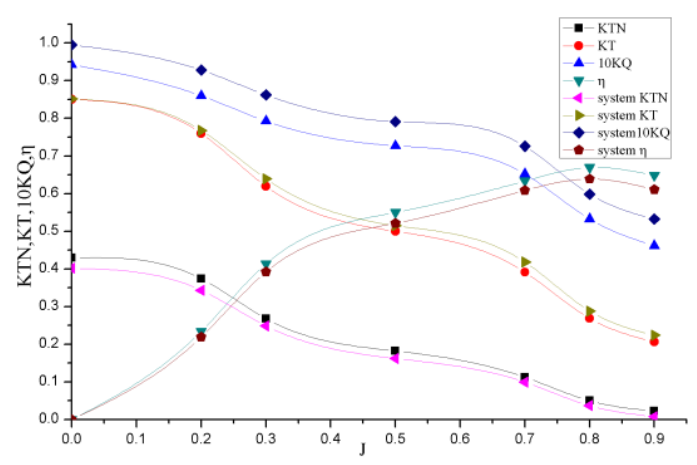

Fig. 5 Comparison of the coefficients: in the open water vs. the ducted propeller-rudder system

The boundary condition of the computational domain is seen from Fig. 4:Velocity inlet boundary condition is set at the inlet boundary and far field; The pressure exportation is used at the outlet boundary; The MRF is used at the region with propeller; The area where the ektexine of duct and rudder are is all the static region; The interface between propeller-rudder region and its surrounding region, in front of screw and peripheral inflow are all set interface boundary condition because of the difference grid between this two plane; The grid at the interface between the propeller and rudder region are the same, thus, this interface was set as interior; The wall of propeller and rudder are set as no-speed-slip wall.

\section{Results and Discussion}

\subsection{Numerical Model}

Take the $R N G k$ - $\varepsilon$ model as the turbulent model, and assume that the scalable wall function is close to the hull wall. The first order upwind scheme is used for numerical discretization, and the method of $M R F$ is used to rotate the model about $\mathrm{z}$ axis(positive direction) at the propeller region. Vari-

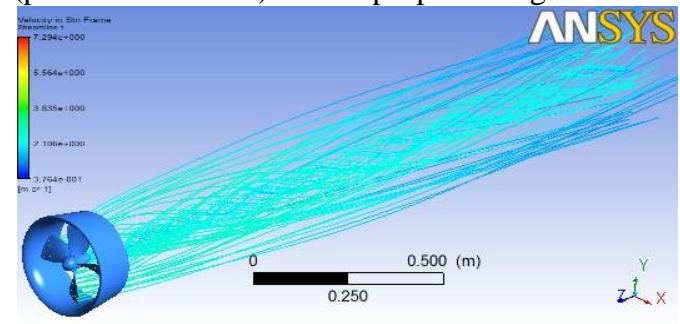

(a) ducted propeller without rudder ous advance coefficients of ducted propeller are used in the calculation, such as $0.2,0.3,0.5,0.7,0.8$ and 0.9 . The rotational speed is assumed to be a constant, 10r/s. Then the inlet-water velocity can be calculated according to $J=v / n D$. The main frequency of computing machine is $2.9 \mathrm{GHz}$ and the inner storage is $4 \mathrm{~GB}$.

Since the rudder can be regarded as a part of the hull, the thrust or resistance due to the rudder may affect the efficiency of the ducted propeller-rudder system, even the whole hull. Therefore, three different coefficients are defined, including the thrust coefficient, torque coefficient and efficiency of the system $(5-7)^{[7]}$ :

$K_{T}=\frac{T_{d}+T_{j}+T_{r}}{\rho n^{2} D^{4}}$

$K_{Q}=\frac{Q}{\rho n^{2} D^{5}}$

$\eta=\frac{J}{2 \pi} \cdot \frac{K_{T}}{K_{Q}}$

where $T_{d}, T_{j}$ and $T_{r}$ correspond to the thrust made by duct, propeller and rudder respectively.

Some results are shown in Fig. 5. The performance of ducted propeller in open water seems to be similar to the hydrodynamic performance of ducted propeller with rudder. When the rudder is installed behind the propeller, the thrust coefficient of duct is lower than that in open water. Meanwhile, the thrust coefficient of propeller increases, and especially the torque coefficient has been increased significantly. However, compared with the performance in open water, the efficiency of performance installed with the rudders, except for the inflection point that appears at $\mathrm{J}=0.8$.

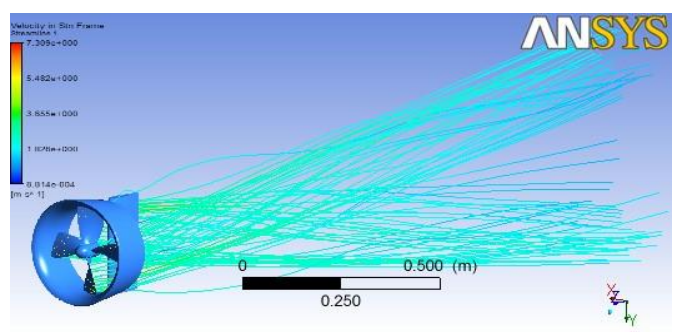

(b) ducted propeller with rudder

Fig. 6 Water particle orbital path behind propeller 


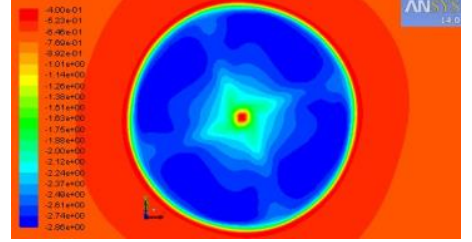

(a) $\mathrm{Z}=-0.067$ without rudder

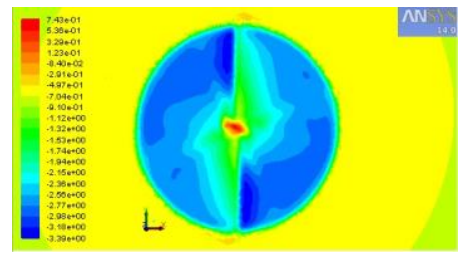

(b) $\mathrm{Z}=-0.067$ with rudder

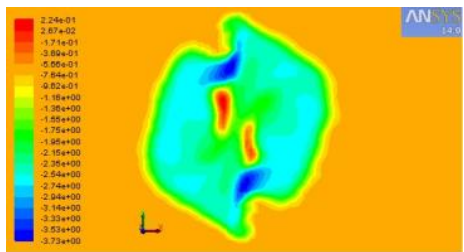

(c) $\mathrm{Z}=-0.22$ with rudder

Fig. 7 The induce axial velocity distribution of cut plane

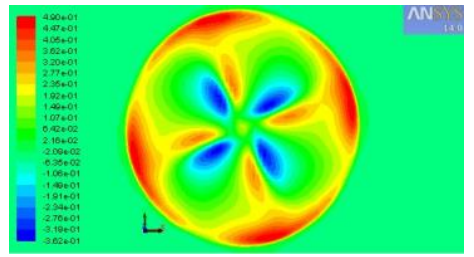

(a) $\mathrm{Z}=-0.067$ without rudder

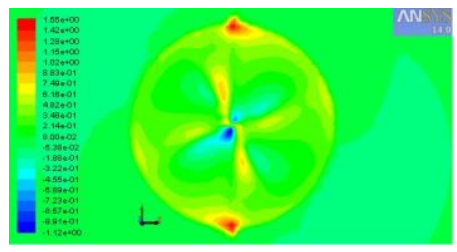

(b) $\mathrm{Z}=-0.067$ with rudder

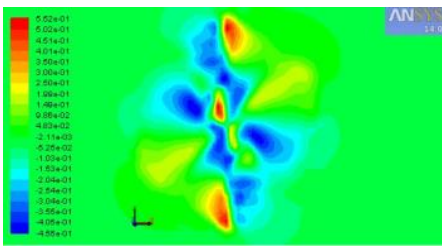

(c) $\mathrm{Z}=-0.22$ with rudder

Fig. 8 The induce radial velocity distribution of cut plane

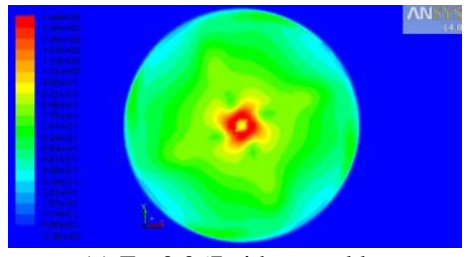

(a) $\mathrm{Z}=-0.067$ without rudder

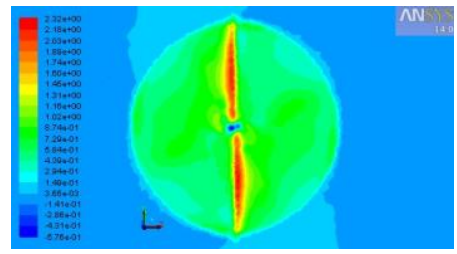

(b) $\mathrm{Z}=-0.067$ with rudder

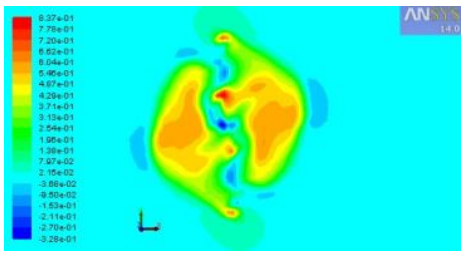

(c) $\mathrm{Z}=-0.22$ with rudder

Fig. 9 The induce tangential velocity distribution of cut plane

\section{Rudder's Effects on Wake Field of Ducted}

\section{Propeller}

In order to study the existence of rudder which may have influence on the wake field of ducted propeller, the trawling condition of trawlers $(\mathrm{J}=0.3)$ is selected and the difference between the wake field of ducted propeller with rudder or without rudder is analyzed.

We can see from the picture of water particle orbital path behind propeller: the trajectory of water particles has been changed obviously: when there is the rudder, the water particles behind the propeller do rotate little, however, they are extended (or aligned) along both sides of the rudder in the vertical direction.

Then, the plane $\mathrm{Z}=-0.067 \mathrm{~m}$ (between the duct and rudder) and $\mathrm{Z}=-2.2 \mathrm{~m}$ (after the rudder)in domain are further considered, respectively. The velocity dis- tributions at these planes are compared at trawling condition of trawlers $(\mathrm{J}=0.3)$

The Figures from 7 to 9 show that : The existence of the duct uncovers the velocity distribution at the cut plane inside and outside, and makes the internal and external domain that the velocity distribution of the cut plane between the duct and rudder entirely different. The velocity distribution are almost centrosymmetric. The radial and tangential velocity distributions at the outside of duct are almost constant. However, they shows quite different at the cut plane behind the rudder, if compared with those in the open water of the ducted propeller.

From Fig. 7, it can be concluded: due to the existence of duct, the lamellar distributions of velocity in and out of the duct are less significant than that with rudder at the section of $\mathrm{Z}=-0.067$, and the velocity distribution at the propeller area is extended drown up and down. At the section of $\mathrm{Z}=-0.22$, there is big difference from the open-water propel- 
ler and the propeller with rudder. In addition, an accelerated region and a decelerated region cab be distinguished at the bottom portside and above starboard of rudder, if seeing from the leading edge to the trailing edge.

For the induced axial velocity distribution of section, there are four leaf-type regions of low speed at $\mathrm{Z}=-0.067$. There is a high-speed zone adjacent to each region of low speed in the radial direction, and this region spreads along the inner wall of the duct after it is connected to duct. As there is the rudder, a region of high-speed zone appears at both the bottom and top of the rudder. However, both the high and low-speed zones almost disappear, when there is the rudder. The uniform velocity region seems to be expanded outward vertically at the section behind the rudder, and a high-speed zone appears at the upper center area of the section simultaneously

For the induced tangential velocity distribution at the section $\mathrm{Z}=-0.067$, the velocity becomes gradually smaller from the inside to the outside in the inner domain of duct, however, there is a significant lower-speed area. The presence of the rudder makes the high-speed region stretched into two long and narrow areas vertically. However, the tangential velocity distribution at the section $Z=-0.22$ is significantly different from the open water wake field of ducted propeller.

\subsection{Impact of Rudder Angles on Hydrodynamic}

\section{Performance of System}

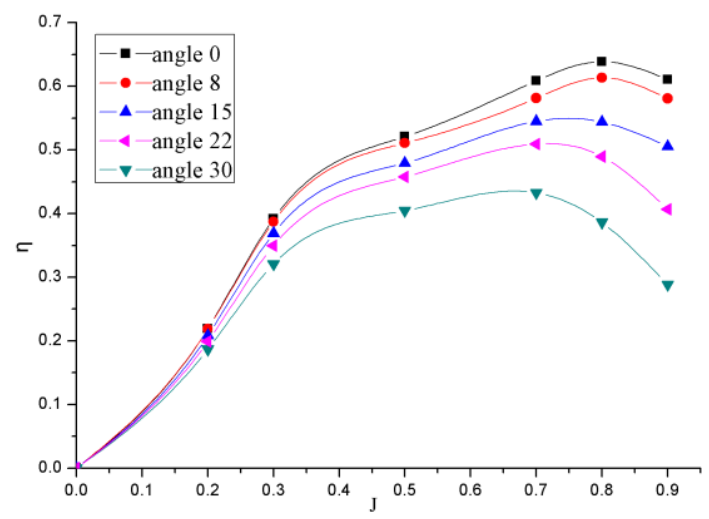

Fig. 10 Comparison of efficiency of propeller-rudder system at different rudder angle
During the voyage, the fishing vessel may have to change their path to avoid the deviation from the predetermined route or chase shoal. Therefore, for the purpose of studying the impact of different rudder angle on hydrodynamic performance of ducted propeller-rudder system, we select different rudder angles, $8^{\circ}, 15^{\circ}, 22^{\circ}$ and $30^{\circ}$.

The selection of the computational domain, meshing and settings of solving parameter are the same as that shown in the paper published.

From Fig. 10 shown above, we can conclude: the efficiency of ducted propeller-rudder system continuously decrease with the increase of rudder angle. Besides, the bigger the advance coefficient is, the reduction of efficiency decrease faster.

\section{Conclusions}

In this paper, the softwares ANSYS and Fluent are used to calculate and investigate the hydrodynamic performance of the ducted propeller and the ducted propeller-rudder system. Some conclusions can be made based on the analysis:

The rudder may help to increase the thrust coefficient and the torque coefficient, however, the thrust coefficient of duct and the efficiency of the propeller may be decreased.

There are significant differences between the wake field of the ducted propeller with or without rudder: Water particles behind the propeller do not rotate too much, but extend along both sides of the rudder in the vertical direction.

Due to the rudder, the velocity distribution in front of the rudder can be separated into two distinct regions: the open water and the area behind the rudder for the propeller with rudder.

The efficiency of ducted propeller-rudder system continuously decreases with an increasing rudder angle. Besides, the bigger the advance coefficient is, the faster the reduction of efficiency is.

In future work, the model test may be carried out to verify the findings shown in this paper based on CFD method.

\section{Acknowledgments}

The work is financially supported by Public Welfare Project of Ministry of Agriculture, with the research topic ' Key Technologies of Energy-saving and Product Development of the Dynamic System of Fishing Vessels). The grant number is 201003024 . 


\section{References}

[1] S.HUANG, theoretical and experimental studies of interaction between propeller and rudder [M].Harbin Engineering University Press.2007

[2] W.H.Isay. On the interaction Between Ship Rudder and Screw Propeller.Schiffstechnik.12(12), 1965

[3] S.Tsakonas,W.R.Jacobs,M.R.Ali. A Theory for the Propeller-Rudder Interaction.Report SITDL-6-1284.Stevens Institute of Technology. 1986
[4] S.Tsakonas,W.R.Jacobs,M.R.Ali.PropellerRudder Interaction.AD-758-692 1972

[5] ANSYS FLUENT User's Guide.Fluent Inc., 2011

[6] FJ.WANG,Computational Fluid Dynamics Analysis-Principles and Applications of CFD software[M].Tsinghua University Press.2004.

[7] WT.HU,Research on the Hydrodynamic Performance of Rudder with Bulb-Thrust Fins Combination[D].Journal of Harbin Engineering University.2011 